\title{
Spatialisations: Rhythmanalysis and spatial drawing
}

Hannah Quinlivan. School of Art and Design, The Australian National University. art@hannahquinlivan.com.au

Conference paper presented at Cambridge University AHRC DTP Conference: 'Time and Temporality', 14th - 16th September 2016.

\section{Introduction}

Hannah Arendt could not have been more wrong. In her ambitious 1958 book The Human Condition, Arendt wrote that art works' distinguishing characteristic is their permanence. For Arendt, their "durability is of a higher order than that which all things need in order to exist at all; [they] can attain permanence throughout the ages." 1 Yet while Arendt was writing, durability itself was becoming obsolescent, just another stifling orthodoxy to be destroyed in the quest for something new. For as we recognise in hindsight, 1958 was the year that gave birth to 'happenings', the volatilisation of art objects and the rise of temporality as a crucial issue in contemporary art.

Temporality in contemporary art is not a monolithic concept. It operates in multiple registers. One might list velocity, intensity and rhythm as its constitutive elements. In this paper, I will focus on the last of these elements, rhythm, and begin a preliminary unpacking of its manifestations in and through contemporary abstract drawing.

In this paper, I aim to bring the practice of contemporary drawing to the scholarly discussion of rhythm and rhythm analysis to see how the two might complement each other. First, I will begin with a discussion of rhythmanalysis, drawing heavily on Henri Lefebvre

\footnotetext{
${ }^{1}$ Hannah Arendt, The Human Condition (New York: Doubleday Anchor, 1958), pp. 167-168.

${ }^{2}$ Allan Kaprow, 'The Legacy of Jackson Pollock', in Essays on the Blurring of Art and Life (Berkeley, CA: University of California Press, 1993), pp. 1-9.
} 
and Gaston Bachelard. I make the case that drawing as a practice can provide a tool for the practical application of the rhythm analytic method. Second, I will discuss an experimental drawing I have developed over the last eight days in the grounds of Pembroke College for this purpose. Finally, I will turn the analytical gaze back on itself and ask what rhythm analysis can offer to the study of drawing practices.

\section{Part I. Rhythm analysis and how to do it.}

Rhythm analysis is perhaps misleadingly named. It is not, as might be assumed, particularly interested in the analysis of rhythms per se. Instead, rhythm analysis is to be used as a mode of analysis, a tool for understanding structures and relations, raising issues of change and repetition.

Rhythm analysis is perhaps best introduced through its genealogy. Developed by first by Gaston Bachelard and then transformed and extended by Henri Lefebvre, rhythm analysis is a response to Bergson's notion of duration. Duration, for Bergson, is "the immediate data of consciousness", a permanence defined by graduated differences. 3 The key characteristic of Bergsonian temporality is perhaps its continuity, the way in which the past is always constituting the present. There is no space here for discrete instants that can be counted, only a continuous unravelling of duration.

Bachelard, in The Dialectic of Duration sought to build on Bergsonian duration. Bachelard's critique is founded on his observation of the experience of nothingness, a problem for duration as Bergson defined it. Bachelard asserted that continuity did not define duration. Instead, duration is characterised by a dialectic of presence and absence, events and nothingness. Time is defined as a series of breaks. On this basis, "temporal phenomena

3 Gaston Bachelard, Dialectic of Duration (Manchester: Clinamen Press Ltd., 200o). 
must each be studied according to its appropriate rhythm... a precise, concrete duration that teems with lacuna." 4

Beginning from Bachelard's critique of duration, Henri Lefebvre sought to construct a method of analysis on the basis of the observation of rhythms. In his final book, Elements of Rhythmanalysis, Lefebvre identifies rhythm as a critical method of analysis. Through the examination of rhythms, Lefebvre seeks to replace the analysis of "things" with the analysis of relations and flows that change over time.

"Nothing," he writes, "is inert in the world." There are "no things", only "very diverse rhythms, slow or living."5 If every thing is in fact an interrupted flow, the question to ask of an object is not "what is it?" but "by what process was it constituted and how is it sustained?"6 With rhythm analysis, Lefebvre seeks to provide a method to raise and answer this question. Yet, as Paul Simpson notes, Lefebvre has little to say about how rhythm analysis might be done. 7

Yet Lefebvre does sketch a portrait of the rhythm analyst, describing the attitude and orientation required. The first task of the rhythm analyst is to listen, and to listen first of all to the rhythms of the human body. The heartbeat, the pulse, the breath provide a reference point against which all other rhythms are measured. The task is to analyse phenomena with reference to these bodily rhythms, not by "jumping from the inside to the outside..." but by "listen[ing] to them as a whole and unify[ing]

\footnotetext{
4 Bachelard, p. 19.

${ }^{5}$ Henri Lefebvre, Rhythmanalysis: Space, Time and Everyday Life, trans. by Gerald Moore and Stuart Elden (New York: Bloomsbury Academic, 2004), p. 26.

${ }^{6}$ David Harvey, Justice, Nature and the Geography of Difference (Cambridge, Mass: Blackwell, 1996), p. 50.

7 Paul Simpson, 'Apprehending Everyday Rhythms: Rhythmanalysis, Time-Lapse Photography, and the Space-Times of Street Performance', Cultural Geographies, 19.4 (2012), 423-45 (p. 430) <https://doi.org/10.1177/1474474012443201>.
} 
them as a whole... integrating the outside with the inside and vice versa." The rhythm analyst will thus come to "listen' to a house, a street, a town, as an audience listens to a symphony."8

In this context we may understand Lefebvre's critique of the thing. For Lefebvre:

...nothing is immobile.... This object is not inert; time is not set aside... It is only slow in relation to our time, to our body, the measure of rhythms. An apparently immobile object, the forest, moves in multiple ways: the combined movements of the soil, the earth, the sun. Or the movements of the molecules and atoms that compose it... The object resists a thousand aggressions... To the attentive ear, it makes a noise like a seashell. 9

How might this attuned listening take place? Lefebvre's provides an example of the observations from his window overlook a junction in Paris. From this distance, he suggests he is close enough to observe, yet not so immersed in the scene below as to find the multiplicity of rhythms overwhelming and their component parts indistinguishable. He then narrates the rhythms of the street below in halting prose, a kind of observational list.

In this paper, I propose another way of doing rhythm analysis that I hope will overcome some of the shortcomings of Lefebvre's method. Specifically, over the last week I have conducted a rhythm analysis of the Old Court at Pembroke College here at Cambridge using spatial drawing conducted in situ as a means of analyzing the space.

\section{Part II. A rhythm analysis of Pembroke College}

I have spent each day, from early morning until nine at night working in the 'Old Court'.

\footnotetext{
${ }^{8}$ Lefebvre, p. 32.

${ }^{9}$ Lefebvre, p. 30.
} 
The Old Court is bounded by two- and three-story buildings, enclosing a courtyard of over half an acre. The buildings surrounding the manicured lawn house the chapel, the Porter's Lodge, the old library and the hall.

The space where I developed the spatial drawing was a semienclosed passage way, bounded by the chapel on one side, opening through arch ways onto the lawn. The site was well suited to undertaking a rhythm analysis, as it is located half inside and half outside the courtyard space.

The process of rhythm analytic drawing simultaneously combines observation with interpretation and intervention. By occupying the space for around 8o hours, I was able to slow down and become attuned to the space, aware of its flows and currents. I got to know the individuals who use the space on a daily basis: gardeners, porters, cleaners, catering staff, tour guides, academics and students, as well as the transitory crowds of tourists, just passing through.

Other, less human flows soon become evident to the observer. The soft light of the morning catching the dew drops, and the grass glitters and sparkles. This soon passes, as the sun moves overhead and the air gradually warms. Other pulses abound, like the trees in neighbouring court, swaying in the gusts of wind.

These observations are captured and interpreted in my drawing, made from wire and adhesive tape, that I have titled 'Spatialisations'. It responds to these rhythms, tracing the flows of people, quivering in time with the swaying of the trees and sparkling like a mirror in the early morning dew. It does not sit rigid and unresponsive, but hums in time with the pulses of the space. Like a microphone, it absorbs sounds and amplifies them visually. If you could see the melody of the organ music, seeping out of the chapel and drifting through the courtyard, it might look something like this.

But this art work does not sit passive, a solitary watcher on the walls. The act of observation intervenes in the space itself. People come and touch the art work. They speak to me about it, asking 
questions, and offering interpretations of their own. It provides an opening for people to stop, and reflect upon the space, seeing it again in a new way. Like a stone in a creek, it causes eddies and ripples in the everyday currents of college activity.

\section{Part III. Conclusions}

On the basis of this experience, I suggest that spatial drawing has certain advantages for rhythm analysis. As a process for observation, spatial drawing takes time. It cannot be rushed. The physical making process is labour intensive, drawn out over minutes, hours, days and weeks. The process of drawing is like the excavations of an archeologist: at first, the surface rhythms are evident, obvious and superficial. It is only after a period of excavation that you start to uncover the more subtle, slow and fundamental rhythms of space.

Spatial drawing is also a bodily process. The rhythm analyst is reliant on her own body, moving through the space, developing the drawing. As she works through the space and moves through the site, she becomes attuned to it bodily and spatially. Her body is not so much a metronome as a pendulum, moving back and forth with a gait that is at first uncertain and irregular but soon becomes harmonized and rhythmic. Each cycle back and forth gains more information, more momentum. Through making, she must become attuned to the site's materiality and spatiality, a knowledge that comes up through her feet and is lodged in the muscles, more than just a knowledge that comes in through the eyes and ears to the brain. The physical soreness of muscles attest to the rhythms of work, rhythms of work that are ultimately dictated by, and a reflection of the site itself.

This method thus takes seriously Lefebvre's suggestion that "the spatialisation of time" is a precondition for its analysis, and that this operation may "stimulate knowledge at the same time as practice." 10

${ }^{10}$ Lefebvre, pp. 19-20. 
Spatial drawing, as a method of rhythm analysis, is a means for developing an understanding, not a record of an already constructed result. Even as the maker, I cannot predict at the beginning of an artwork where it will lead. It is only through the physical process of making that meaning crystallises and becomes clear. Like any generative analytical work, the results are unknown at the outset. It is a fertile method for developing a new understanding, not a sterile method for the recording of some preconceived notion or argument.

I had intended to conclude this paper with some lessons. My abstract promised that I would present you with a rhythm analysis of the art work itself. Yet having concluded the exercise, I find that I am unable to do so. The value of this method of rhythm analysis is in the way it captures knowledge beyond language. To speak about what has been learnt would be to flatten the material and the embodied knowledge, thereby negating its value. Indeed, if what could be learnt from spatial drawing could be expressed in words, the drawing process would itself be unnecessary. What the drawing process brings is new insights that cannot be expressed in words. This is both its great strength, but also its limitation. The artwork itself must be listened to. As Lefebvre might say, to the attentive ear, it makes a noise like a seashell.

So to finish now will be unsatisfactory, my research only half communicated. As such, I invite you to find a moment to visit the Old Court of Pembroke College and attend to the artwork and its location. If you listen carefully and use your own body as a metronome, you may hear something too. 


\section{Images of 'Spatialisations'}
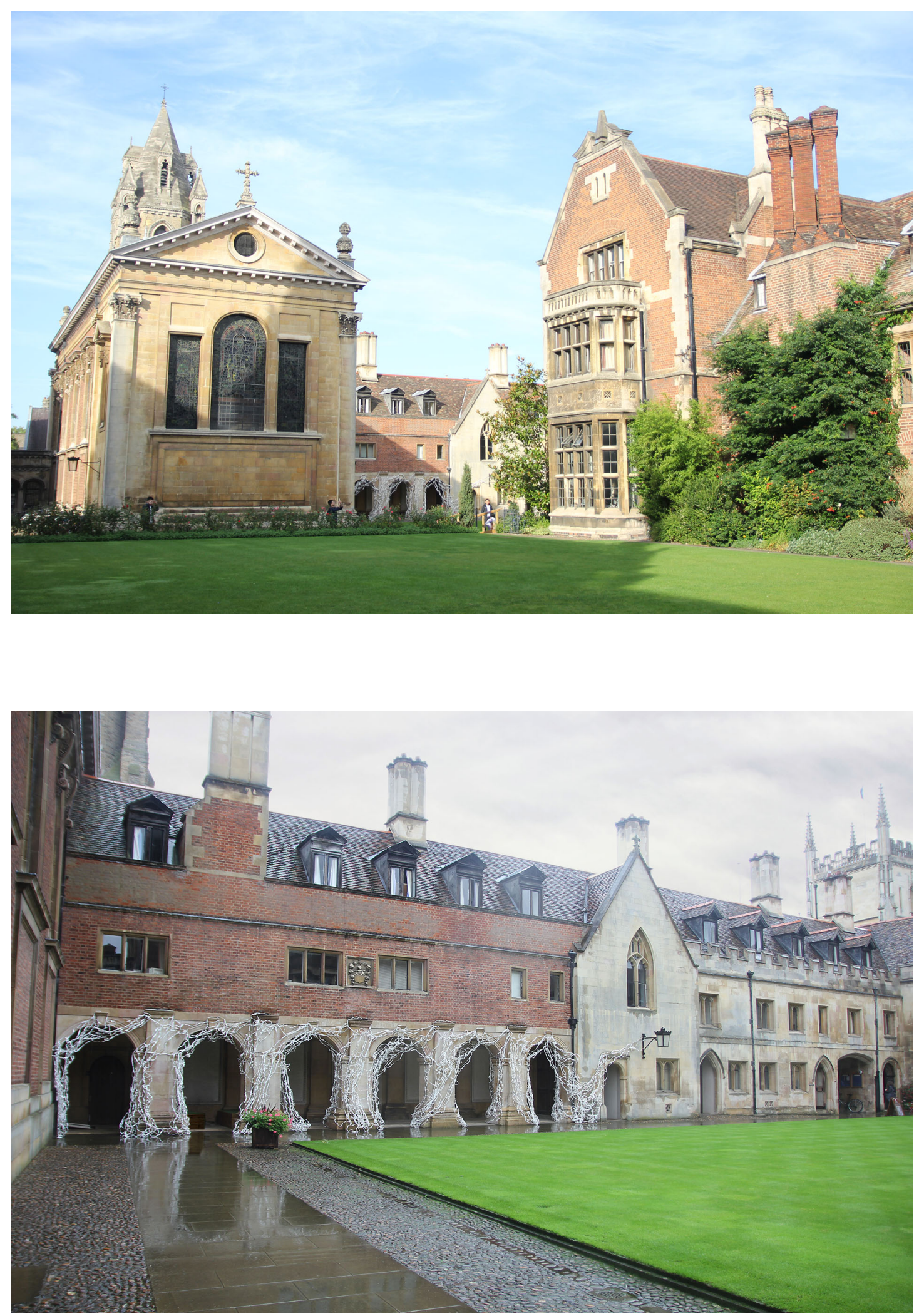

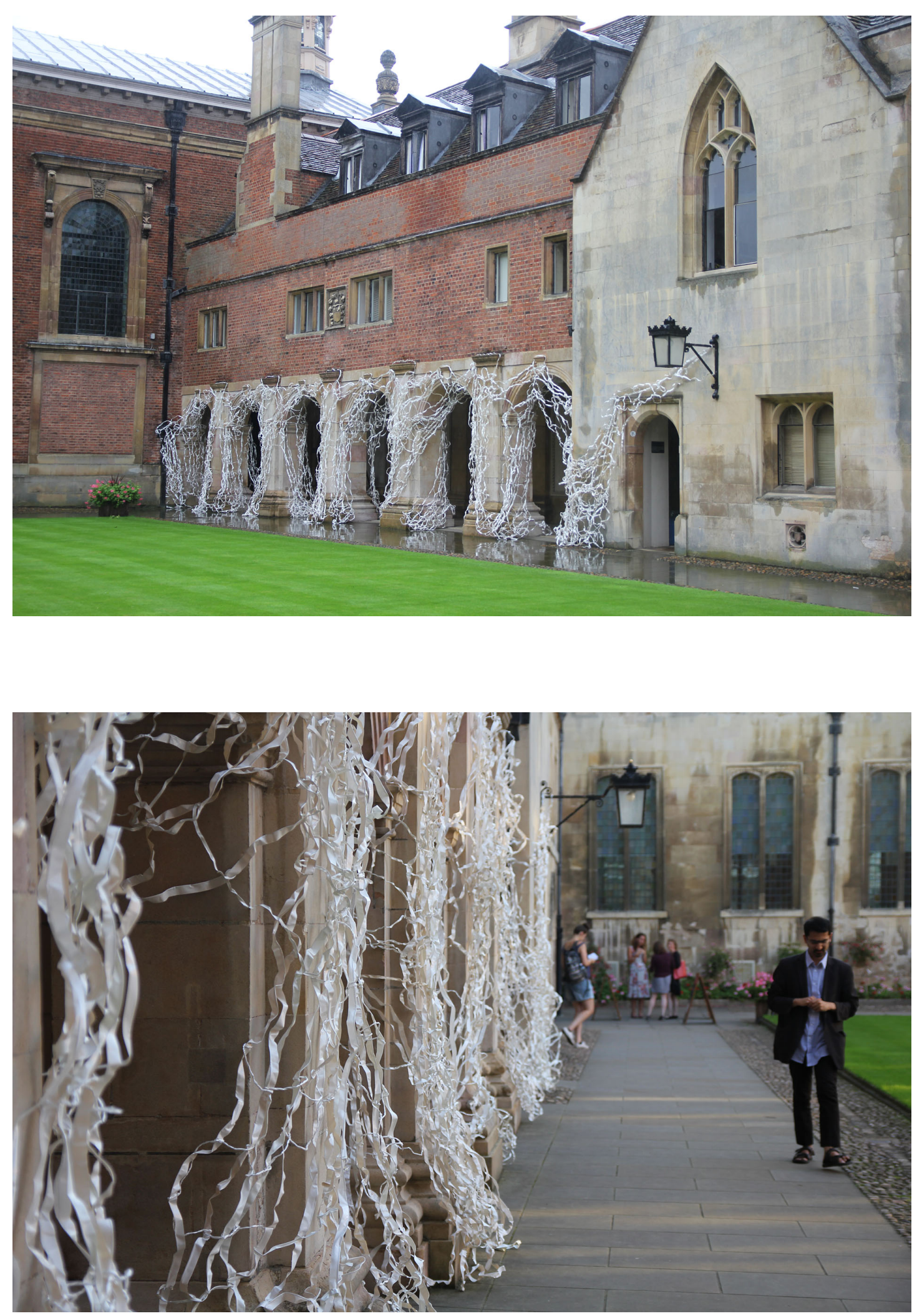

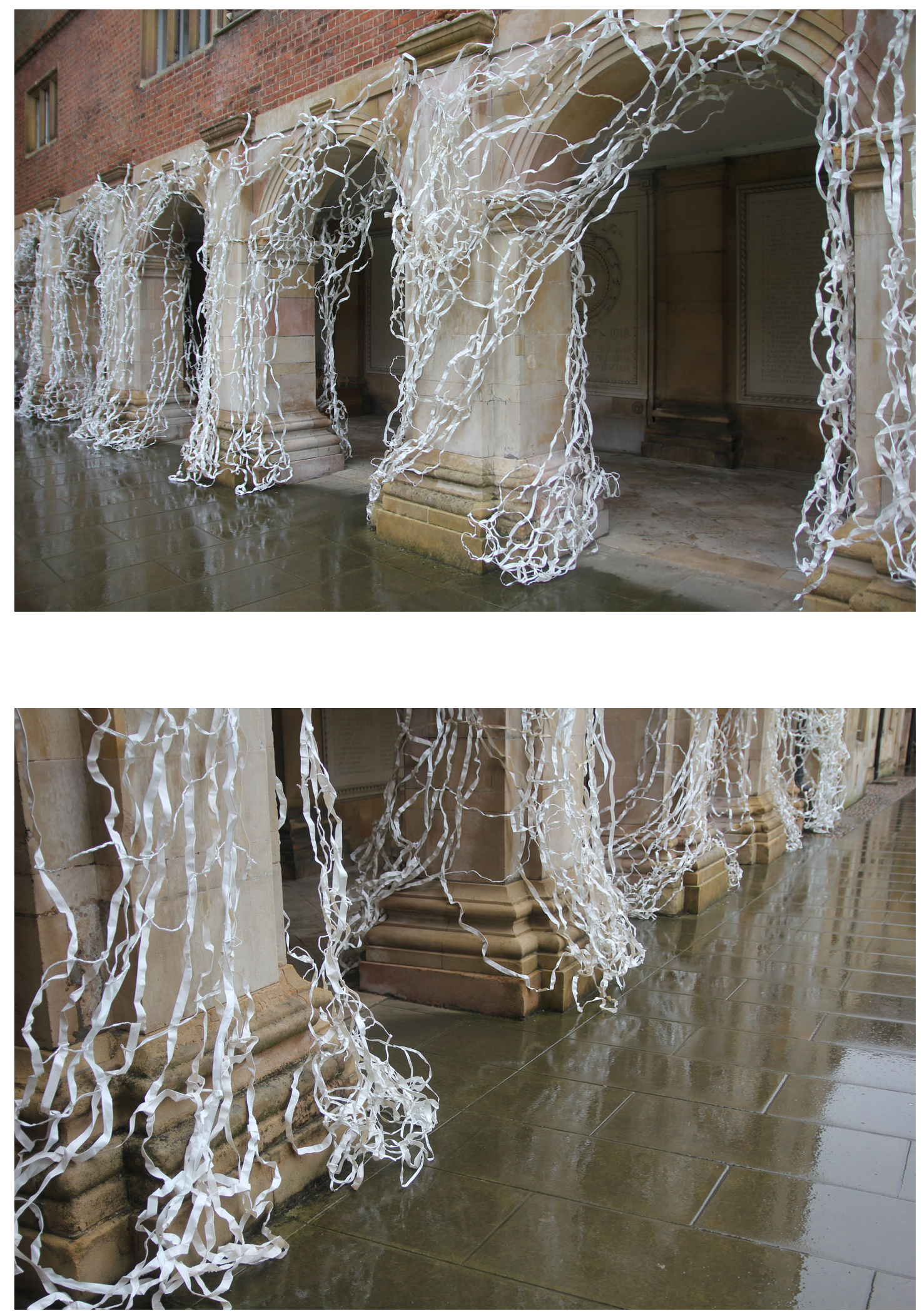

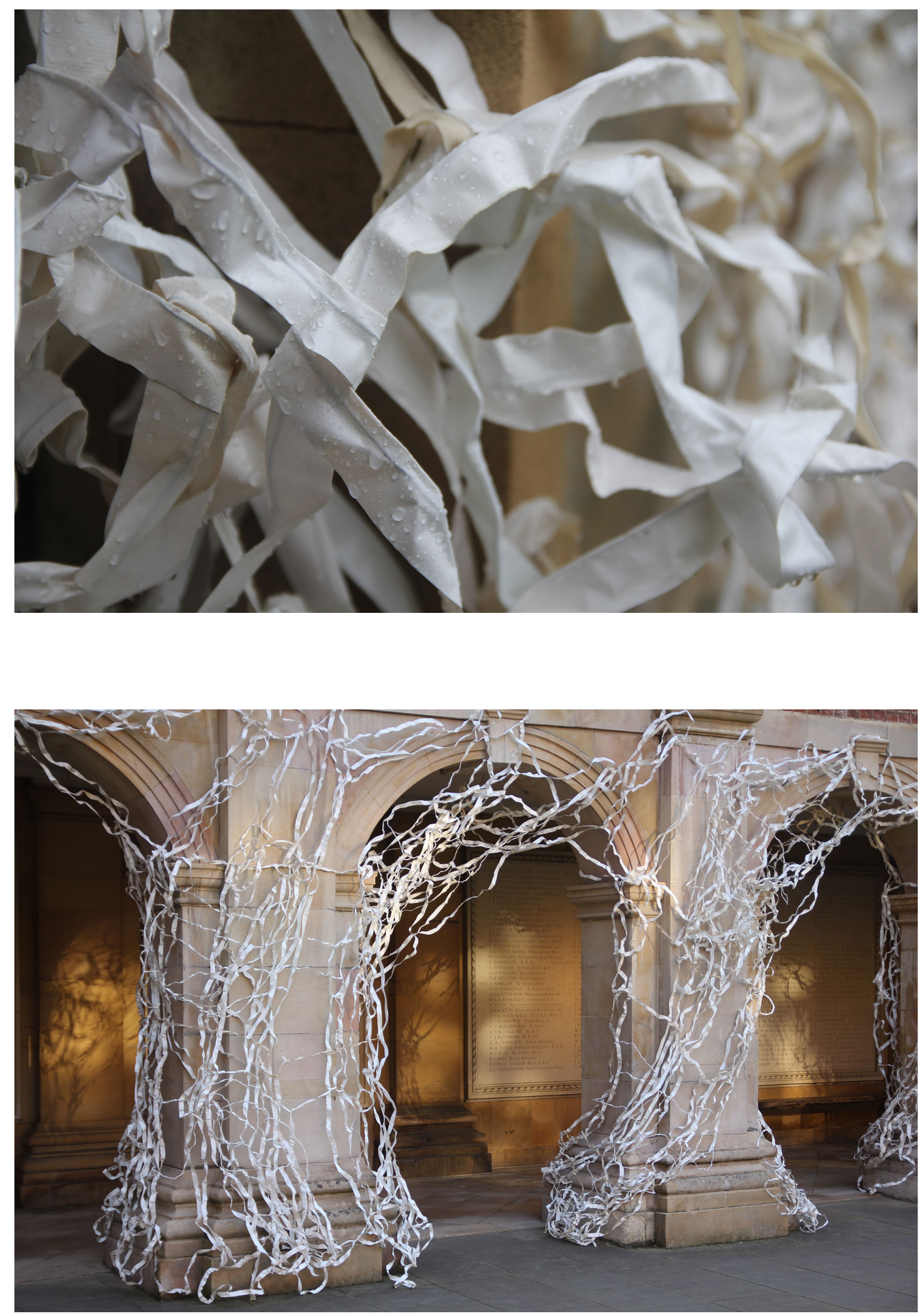

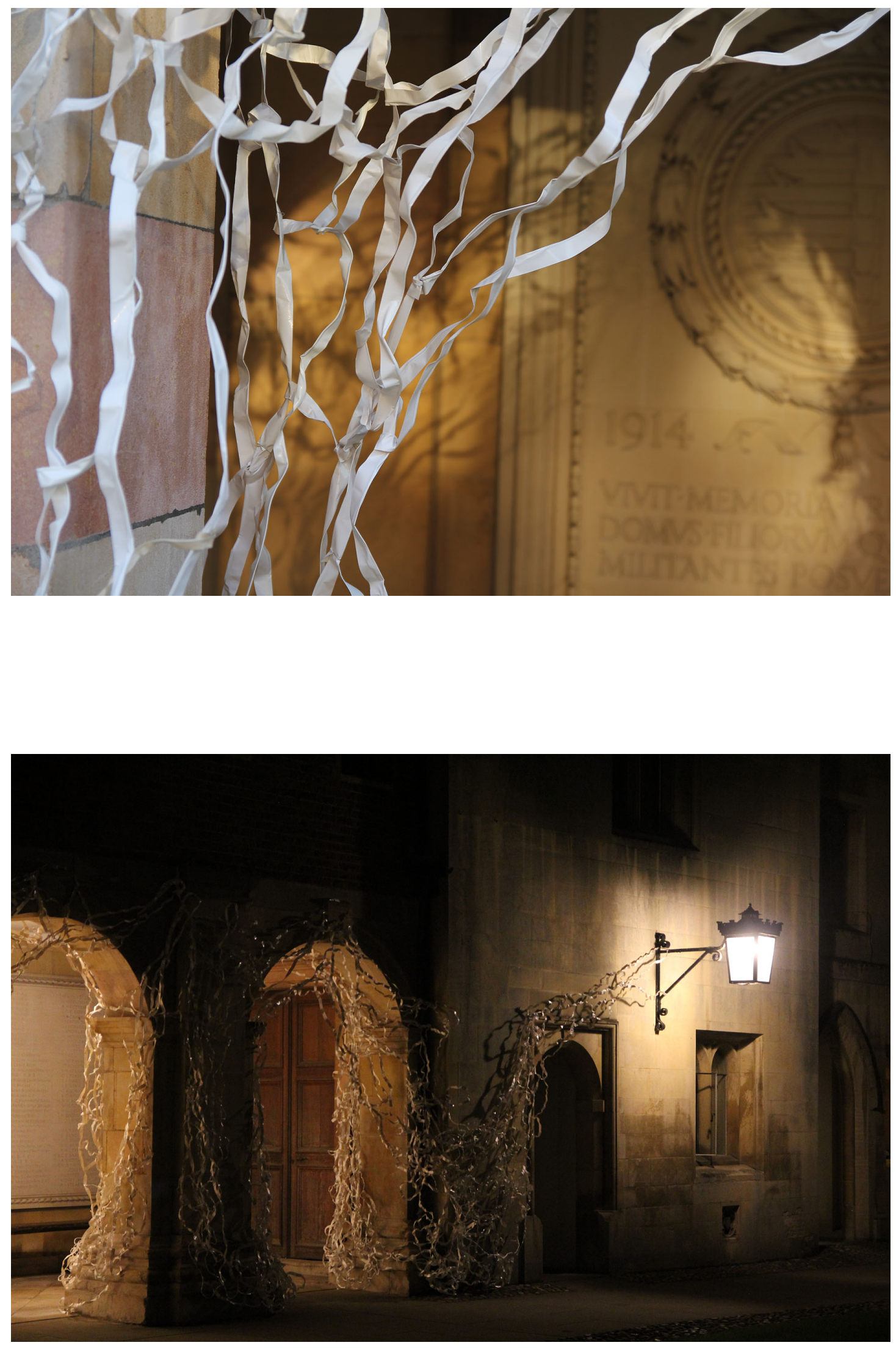


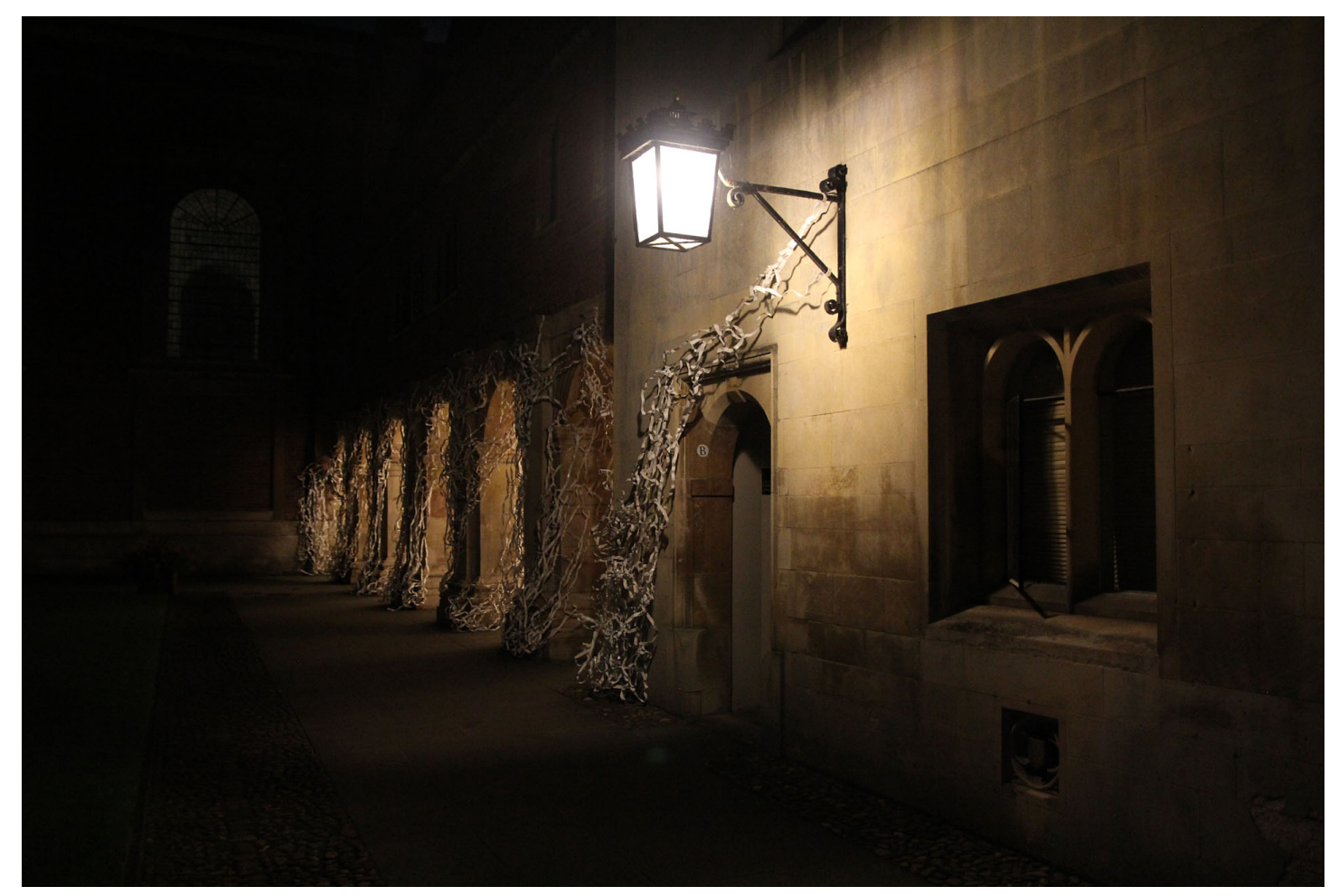

\section{References}

Arendt, Hannah, The Human Condition (New York: Doubleday Anchor, 1958)

Bachelard, Gaston, Dialectic of Duration (Manchester: Clinamen Press Ltd., 2000)

Harvey, David, Justice, Nature and the Geography of Difference (Cambridge, Mass: Blackwell, 1996)

Kaprow, Allan, 'The Legacy of Jackson Pollock', in Essays on the Blurring of Art and Life (Berkeley, CA: University of California Press, 1993), pp. 1-9

Lefebvre, Henri, Rhythmanalysis: Space, Time and Everyday Life, trans. by Gerald Moore and Stuart Elden (New York: Bloomsbury Academic, 2004)

Simpson, Paul, 'Apprehending Everyday Rhythms: Rhythmanalysis, Time-Lapse Photography, and the Space-Times of Street Performance', Cultural Geographies, 19 (2012), 423-45 <https://doi.org/10.1177/1474474012443201> 